\title{
Holistic assessment of a secondary water supply for a new development in
} Copenhagen, Denmark

Rygaard, Martin; Godskesen, B.; Jørgensen, C.; Hoffmann, B.

\section{Published in:}

Science of the Total Environment

Link to article, DOI:

10.1016/j.scitotenv.2014.07.078

Publication date:

2014

Document Version

Peer reviewed version

Link back to DTU Orbit

Citation (APA):

Rygaard, M., Godskesen, B., Jørgensen, C., \& Hoffmann, B. (2014). Holistic assessment of a secondary water supply for a new development in Copenhagen, Denmark. Science of the Total Environment, 497-498, 430-439. https://doi.org/10.1016/j.scitotenv.2014.07.078

\section{General rights}

Copyright and moral rights for the publications made accessible in the public portal are retained by the authors and/or other copyright owners and it is a condition of accessing publications that users recognise and abide by the legal requirements associated with these rights.

- Users may download and print one copy of any publication from the public portal for the purpose of private study or research.

- You may not further distribute the material or use it for any profit-making activity or commercial gain

- You may freely distribute the URL identifying the publication in the public portal 
This is the Accepted Author Manuscript of the article:

Holistic assessment of a secondary water supply for a new development in Copenhagen, Denmark

Science of the Total Environment (2014), pp. 430-439 DOI information: 10.1016/j.scitotenv.2014.07.078

\section{Holistic assessment of a secondary water supply for a new development in Copenhagen, Denmark}

Authors: M. Rygaard*, B. Godskesen**, C. Jørgensen*** \& B. Hoffmann****

*Technical University of Denmark, Department of Environmental Engineering, Miljoevej 113, DK-2800 Kgs.

Lyngby (E-mail: mryg@env.dtu.dk).Phone: +45 45251570

**HOFOR, Ørestads Boulevard 35, DK-2300 København S (E-mail: bego@hofor.dk)

***DHI. Agern Alle 5. 2970 Hørsholm, Denmark (E-mail: clj@dhigroup.com)

**** Aalborg University, Department of Development and Planning, A.C. Meyers Vænge 15, 2450

København SV, Denmark (E-mail: bhof@plan.aau.dk)

\section{Highlights}

- Alternative water supply options are defined for a city development

- Options are assessed in a combined quantitative and qualitative evaluation

- The assessment methods cover economy, environment, health and public perception

- The results expose the multi-faceted consequences of new water supply concepts 


\section{Abstract}

Increasing stress on water resources are driving urban water utilities to establish new concepts for water supply. This paper presents the consequences of proposed alternative water supply options using a unique combination of quantitative and qualitative methods from different research fields. A former industrial harbour area in Copenhagen, Denmark, is currently under development and all infrastructure will be updated to accommodate 40,000 inhabitants and 40,000 jobs in the future. To reduce stress on water resources it has been proposed to establish a secondary water supply in the area as an alternative to the conventional groundwater-based drinking water supply. Four alternative concepts for a secondary water supply have been considered: 1) slightly polluted groundwater for use in toilets and laundry, 2) desalinated brackish water for use in toilets, laundry, and dishwashers, 3) desalinated brackish water for all uses, including drinking water, and 4) local reclamation of rain and gray water for use in toilets and laundry. The concepts have been evaluated for their technical feasibility, economy, health risks, and public acceptance, while the concepts' environmental sustainability has been assessed using lifecycle assessment and freshwater use impact methods. The holistic assessment method exposes conflicting preference solutions depending on assessment criteria, and reveals multi-faceted consequences for choices in urban water management. Not one concept turns out unambiguously positive based on the evaluation criteria included here, but the systematic evaluation will leave decision makers informed on the consequences of their choices.

Keywords: health risk; water reuse; freshwater impact; lifecycle assessment, user perspectives; water supply 


\section{Introduction}

Urban areas are often challenged to find new options for water supply as a response to climate change, urban developments, or new legislation enforcing increased allocation of water to natural flows. Climate change will in many areas reduce available water, which leads to comprehensive adaptation measures from the utilities (Charlton and Arnell, 2011; Grant et al., 2013). Likewise, urbanization and increased allocation of water to natural flows can lead to increased water demands and reduce water resources available for import into the urban area from neighboring catchments. In such cases cities may choose to increase water self-sufficiency instead (Rygaard et al., 2011b). Driven by these challenges utility companies continuously have to make choices regarding the replacement of old infrastructure or preparing new developments under the governance by local and national regulations and authorities. Changes in urban water infrastructure are influenced by political decisions and physical constraints, a situation which often leads to new directions for water management strategies in big cities ( Rygaard et al., 2011b). These choices affect future inhabitants as well as the economic and environmental systems in place for several decades to come, and therefore there is a substantial focus on decision support tools such as environmental impact assessment (Chen et al., 2012), cost-benefit analysis (Van der Bruggen et al., 2009) and risk assessment (O'Toole et al., 2012) that can be used in the planning of urban water infrastructure. Recently, increased attention has also been directed towards public perception analysis in an attempt to understand what drives people to accept or reject new concepts for urban water management (Lamichhane and Babcock, 2013; Mainali et al., 2013). For example, it has been investigated how different notions on water types will influence public acceptance (Dolnicar et al., 2014).

Usually, such tools have been used in separate processes, and since decision-makers have to base their choice on the outcome of the selected assessment methods it becomes important that the combined evaluation covers the wide aspects of introducing new urban water infrastructure. From this follows a second challenge that the decision makers have to make decisions across various studies, and they are often left with the task to combine the results provided by various tools in their own judgment. 
As a response to these challenges we chose to combine quantitative evaluation tools, focussed on the economy, risk, and environmental performance, with a qualitative stakeholder survey to facilitate a holistic decision-making in line with alternative secondary water supply options. The evaluation is summarised in a multi-criteria assessment that reveals pros and cons of each alternative concept for water management.

As a case study for demonstrating the holistic assessment of urban water concepts we use Nordhavn (Northern Harbour), Copenhagen, a former industrial harbour area that will be developed from an industrial and harbour area into a new urban district integrated into the Danish capital city Copenhagen (CPH CP, 2012). When finished the area is expected to accommodate 40,000 inhabitants and 40,000 jobs. Although Denmark is usually not considered a water-scarce country, the capital region faces water resource challenges due to groundwater pollution and the implementation of the EU Water Framework Directive, which will prioritize water from public water supply to environmental flows (European Commission, 2012). For these reasons, the municipality, landowners and the water utility consider to establish a water supply secondary to the existing groundwater based water supply of Copenhagen. Four different concepts for secondary water supplies are proposed and these are evaluated against a business-as-usual concept, i.e. to extend the existing water supply in City of Copenhagen into Nordhavn.

The application of the holistic assessment method for Nordhavn aims to answer the following research questions: 1) How can quantitative assessments of the economy, environmental impacts, and health risks, in combination with the qualitative assessment of public acceptance, inform urban water system decisionmakers? And 2) Will a secondary water supply be a sustainable solution for a new development in Copenhagen, Denmark? In an attempt to answer these two questions, our study highlights the integration of multiple evaluation criteria applied to a specific urban development plan in a big city. In the following we present method and results from this work. Further details on the project has been reported elsewhere (Rygaard et al., 2013). 


\section{Method}

The project was conducted in two phases. First, four water supply concepts were defined and described, and secondly these concepts were evaluated regarding economic and environmental impacts, a risk assessment, and user perspectives on introducing an alternative water supply in Nordhavn.

\subsection{Defining secondary water supply concepts for Nordhavn}

Nordhavn's development is scheduled for completion in 2060 in several stages, the first of which has already commenced. Since details are only available currently for the first stages, we have proposed concepts that would eventually cover the fully developed area, and then scaled costs and other impacts accordingly to the stages with known details. This was necessary, since water infrastructure designed for smaller neighborhoods would be disproportionally more expensive to build per inhabitant and would not reflect actual costs and impacts over time.

The development master plan for Nordhavn requires a wide range of sustainability measures in the management of energy, transport, buildings, and resources, including water services (CPH CP, 2012). Based on the master plan and consultancy with stakeholders (not reported here) we defined four concepts that would answer the identified needs for Nordhavn, Copenhagen, and the development of water management and technologies in Denmark in general. It was not the intention to explore all possibilities for Nordhavn, but key examples of possibilities for development that will meet different objectives were prioritized. The observations and objectives identified in this respect were:

1. Copenhagen has a formulated strategy to exploit water which is secondary in quality to drinking water for non-potable uses (Københavns Kommune, 2012).

2. Copenhagen is situated at the entry to the brackish Baltic Sea, which could be a feed water source at low cost via a low-impact desalination scheme (Muñoz and Fernández-Alba, 2008; M Rygaard et al., 2011a). 
3. An alternative water supply in Nordhavn would support shaping the identity of a new urban development.

4. An alternative water supply in Nordhavn would spearhead the ambitions of local technology suppliers to demonstrate new solutions for international water management challenges.

Danish water supply is based on groundwater only, and the vast majority of this abstracted groundwater requires only simple treatment (aeration and sand filtration) or no treatment at all before distribution. It is often stated that the entire Danish water supply is based on "unpolluted groundwater," although a few local exceptions exist. As such, any large-scale implementation of an alternative water supply would be a paradigm shift in Danish water supply management.

\subsection{Evaluating concepts}

The alternative concepts are evaluated relative to a baseline, defined as "business-as-usual," where the water distribution network is extended from Copenhagen into the Nordhavn. The concepts are evaluated on economy, environmental impact, risk of infection and user perspectives as described in the following.

\subsubsection{Economy}

The economic evaluation is based on estimations of investment and operational costs calculated as net present value (NPV) for a 50-year lifetime and at 3\% interest rate, which are assumed average values based on current planning practice in the utility. Costs are based on the local water utility's estimations of investment in pipes, in and outside buildings, production facilities for primary and secondary water supply, and operational costs pertaining to both production and pipes.

\subsubsection{Environmental impact assessment}

The environmental impact has been calculated using a standard lifecycle assessment (LCA) combined with calculations of impacts on freshwater resources. Impacts a calculated for a functional unit that is $1 \mathrm{~m}^{3}$ of water distributed in Nordhavn. The method follows the ISO standard (ISO, 2008), with two points of 
departure: 1) In order to assist in the decision-making process we present the normalized results in person equivalents (PEs) and the weighted result, where all environmental impacts can be added up into one single score and presented as a person equivalent targeted (PET) figure. One PE (person equivalent) is interpreted as the average pollution load caused by one person in Europe, while PET is the PE weighted by the perceived importance of the impact category, and 2) We review the LCA internally and not through an external reviewer.

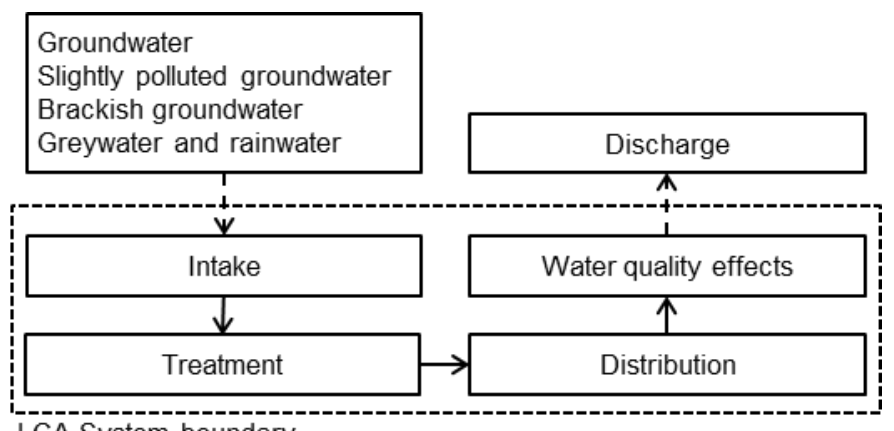

LCA System boundary

Figure 1. System boundary for the environmental lifecycle assessment.

The LCA system boundary included the intake of water from one of four water resources, treatment, distribution, water quality effects, and discharge after use (Figure 1). Water quality effects cover impacts of reduced water hardness, as discussed by Godskesen et al. (2012). The impact categories, units, and calculation methods used for the standard lifecycle assessment are summarized in Table 1. 
Table 1. Impact categories, units and calculation method used in the lifecycle assessment. Impacts have been calculated using ReCiPe (Goedkoop et al., 2009) and USE-tox (Rosenbaum et al., 2008) methods.

\begin{tabular}{l|l|l|l}
\hline Impact area & Impact category & Normalization unit & $\begin{array}{l}\text { Calculation } \\
\text { method }\end{array}$ \\
\hline Environment & $\begin{array}{l}\text { Climate change } \\
\text { Terrestrial acidification } \\
\text { Photochemical oxidant formation }\end{array}$ & $\begin{array}{l}\mathrm{CO}_{2} \text { equivalents } \\
\mathrm{SO}_{2} \text { equivalents } \\
\mathrm{C}_{2} \mathrm{H}_{4} \text { equivalents } \\
\mathrm{NO}_{3}^{2-} \text { equivalents }\end{array}$ & $\mathrm{ReCiPe}$ \\
& Freshwater eutrophication & $\mathrm{Fe}$ equivalents & \\
\hline Resources & Metal depletion & $\begin{array}{l}\text { CTUe (comparative toxic unit } \\
\text { ecosystem) } \\
\text { CTUh (comparative toxic unit } \\
\text { human) }\end{array}$ & USE-tox \\
\hline Toxicity & Ecotoxicity & & \\
& Human toxicity (cancer) & \multicolumn{2}{l}{} \\
\hline
\end{tabular}

Weighting was done through the PE LCIA Survey 2012 method in which weighting of individual impact categories are based on 245 LCA experts' assessment of the impacts to be addressed most urgently (PE International, 2012). All environmental, resource, and toxicity impacts, excluding freshwater withdrawal impacts, were modeled using GaBi software (Baitz et al., 2012). Freshwater withdrawal impacts were calculated as described in Godskesen et al. (2013) and evaluated as an environmental impact category in its own right, as freshwater withdrawal impact is not yet part of the standard LCA method. To check for robustness a simple sensitivity analysis was employed with estimated impacts for four alternative scenarios: 1) A $50 \%$ reduction in material consumption, to illustrate the environmental significance of infrastructure investments; 2) a $50 \%$ reduction in water quality impacts, to illustrate the significance of effects caused by excessive scaling and other impacts related to the hardness level of the supplied water. To illustrate the importance of future changes in power production, environmental impacts were assessed based on the predicted energy mix of 3) 50\% renewable electricity production and 4) $100 \%$ renewable electricity production. For scenario 1) a 50\% reduction reflects a marked reduction in impacts from material consumption, for example induced by choosing low impact materials or increased lifetime of installation. A $50 \%$ reduction in water quality impacts in scenario 2 ) is assumed to reflect a situation where people's behaviour (e.g. dosage of soap), lifetime of installations, and energy losses are much less improved by the 
changed water quality than anticipated. The power production is currently changing from fossil based fuels to renewable energy sources and scenarios 3) and 4) correspond to the official political targets for Danish power production set for 2020 and 2035 respectively (The Ministry of Climate Energy and Building, 2013).

\subsubsection{Risk of infection}

Microorganisms were considered the most likely threat to human safety in the proposed systems. A quantitative microbial risk assessment (QMRA) was conducted with Norovirus as a model organism. Norovirus was chosen because it is the pathogen most likely to cause infection after intrusion into the proposed water systems, because of its potential presence in well-protected groundwater (Borchardt et al., 2012), its relatively long lifespan in groundwater (Seitz et al., 2011), low sand filtration efficiency in the absence of coagulation (Shirasaki et al., 2010), high concentration in the faeces of infected individuals (Tu et al., 2008), and high contagion rate (Teunis et al., 2008). A reverse quantitative microbial risk assessment (QMRA) was carried out assuming that the water is used for toilet flushing and laundry. Average concentrations of Norovirus in the supplied secondary water at an average infection risk probability of approximately $10^{-4}$ per year, which is the acceptable risk of infection for drinking water applied by the US EPA (Lechevallier and Buckley, 2007) were calculated by Monte Carlo simulation with @Risk Pro ver 6.01. Dose-response relationships for infection (aggregated), proposed by Teunis et al. (2008), were used. During toilet flushing it was assumed that $10 \mu$ is ingested three times a day (NRMMC et al., 2006). During laundry it was assumed that $30 \mu \mathrm{l}$ is transferred to the hands (O'Toole et al., 2009), that $3 \%$ is on the fingertips, and $34 \%$ thereof is transferred to the mouth (Rusin et al., 2002), for one wash per day. A cross-connection was assumed to result in exposure by drinking $0.86 \mathrm{~L}$ (lognorm distribution with stdev $=0.48$. (Westrell, 2006)), and occur with probabilities evenly distributed between 1:1000 (NRMMC et al., 2006) and 1:10,000 (Storey et al., 2007) per apartment over one day and impacting the same apartment only. Doses were assumed to be Poisson distributed. Concept 3 is not analysed since it is equal to the do-nothing situation (CO) and the delivered water is treated to drinking water quality standards. 


\subsubsection{User perspectives}

The study was based on a dynamic understanding of water management and urban development as being part of a transition agenda towards sustainability in Copenhagen. Although large technological systems, including technical solutions, investments, preferences, and professional as well as user practices in water management, are characterized by inertia, there are ongoing changes and new solutions, values, and argumentations that were unknown only a few years ago are now becoming mainstream. One example is the current focus on the demand side, which has replaced the earlier aim of an unceasingly growing supply. As part of this the former division within the water system between the users on the one side and the professional service providers on the other side are being challenged (Lindegaard, 2008). Now users need a deeper knowledge of the system and the systems rationales to accept and participate in water-saving schemes. Another example is that until 2001 it was not permitted to use rainwater for flushing toilets in Denmark (Danish Ministry of the Environment, 2001). Prior to that, and for safety reasons, only potable water was allowed to flow into a house. The project covered in this paper is thus part of this ongoing transition of the water system. Therefore, a qualitative and explorative study of user roles and preferences was conducted, in order to highlight a wide range of values, issues, and dynamics at stake in relation to the selected scenarios. The term 'users' in this study refers to private households.

The study comprises five supplementary elements: 1: A quick poll on the local utility website for a period of three weeks; 2: A telephone survey of inhabitants in a new housing area in the South Harbour; 3: A focus group interview with 5 citizens randomly selected from the quick poll; 4: Individual interviews with 8 inhabitants in two different building blocks in Copenhagen with experience of secondary water use; and finally 5: Two workshops with 19 key individuals and professionals in relation to water management, urban development, and/or civic participation, including one with the project group. Hence a total of 32 people participated in the interviews, focus groups, and workshops. 95 users responded to the quick poll, and 50 users responded to the survey. This combination is assessed as reasonable to provide a broad set of values, issues and dynamics in relation to the change towards use of secondary water. The interviews and 
workshops were semi-structured, with guiding issues thus open to new perspectives, details, and variations. In order to overcome a positive bias towards the environmentally friendly, the interviews took starting point in daily water practises and technical installations in the households.

\section{Results and discussion}

The main results of the holistic assessment are presented and discussed in the following, starting with the presentation of the proposed concepts for alternative water supply.

\subsection{Four concepts of secondary water supply for Nordhavn}

The four concepts alternative to C0 Business-as-usual were: C1 Polluted Groundwater, C2 Desalination Dual Reticulation, C3 Desalination Drinking Water, and C4 Rain and Gray Water. The C0 Business-as-usual concept and the first three alternative concepts, $\mathrm{C} 1-\mathrm{C} 3$, were built with off-the-shelf technology in mind (Figure 2). Concept 4 Rain and Gray Water was proposed as a demonstration project and as such it would depend on new technology not available on the market. 
Co

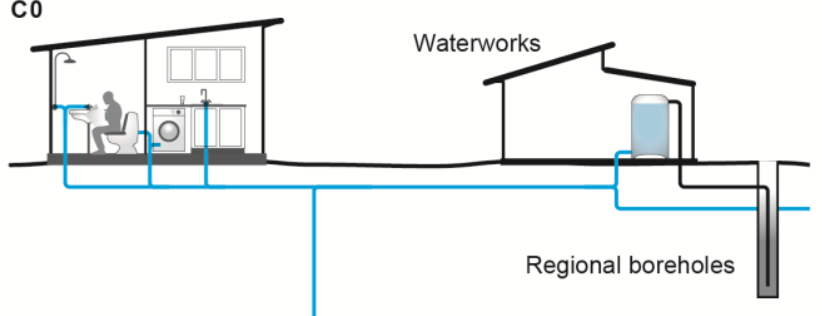

C2

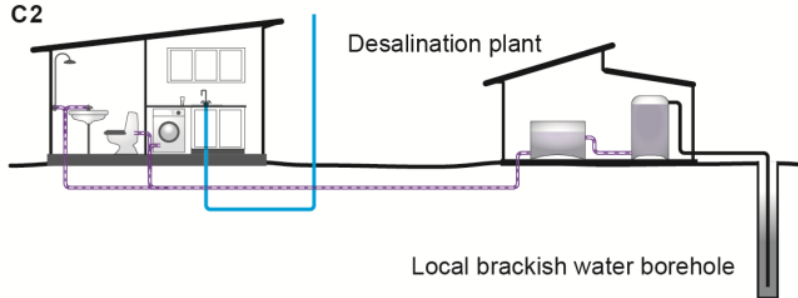

C1

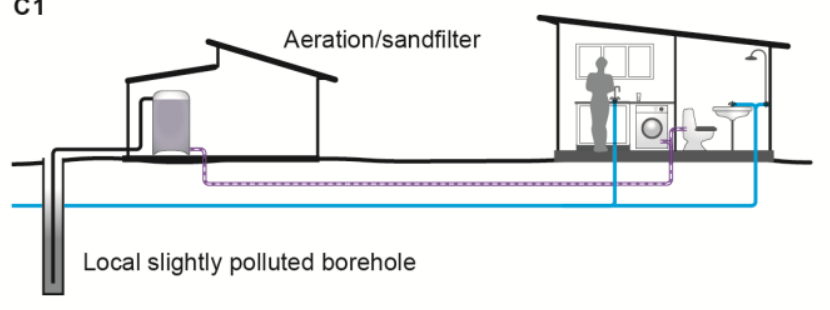

C3

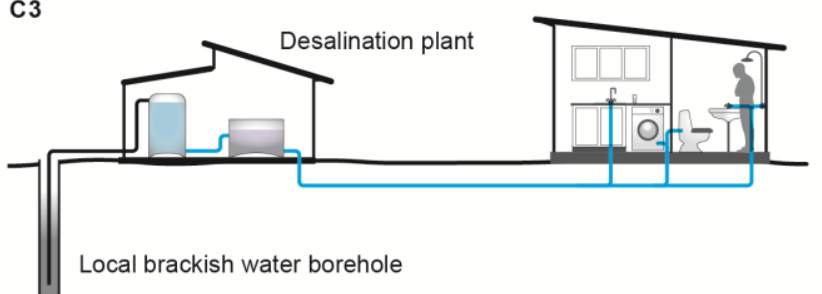

C4

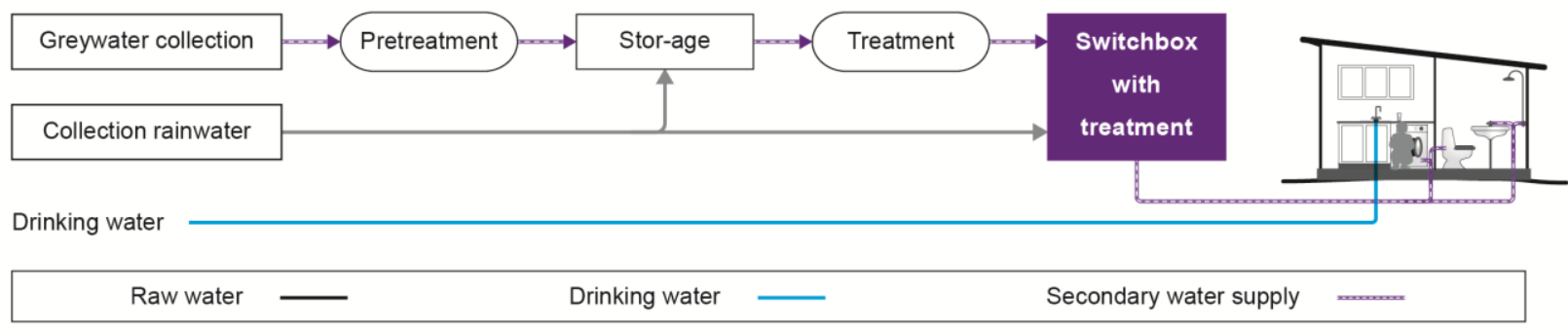

Figure 2. Concepts: CO Business-as-usual, C1 Polluted Groundwater, C2 Desalination Dual Distribution, C3

Desalination Drinking Water, and C4 Rain and Gray Water, proposed as water supply options for Nordhavn.

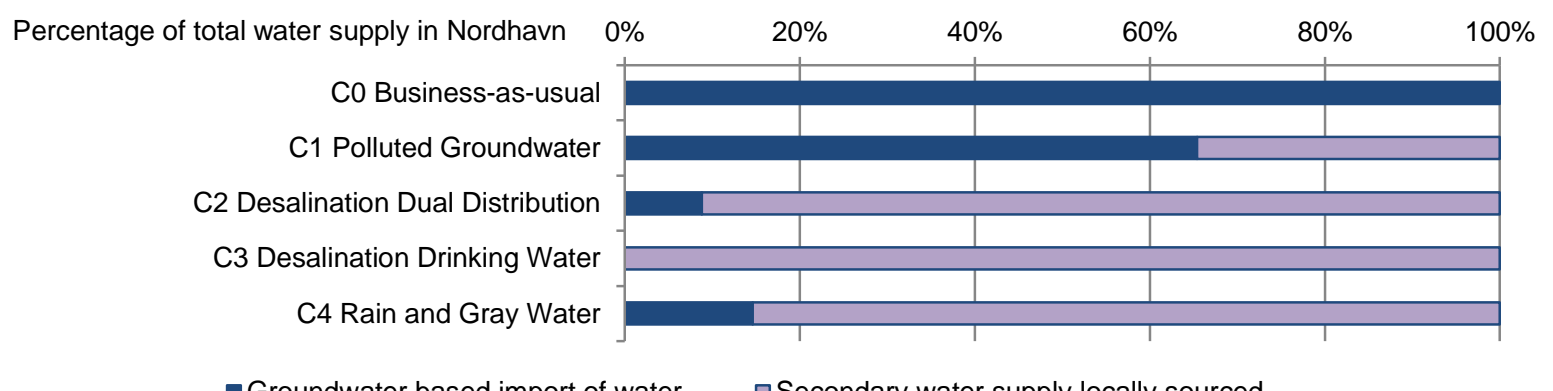

- Groundwater based import of water $\quad$ QSecondary water supply locally sourced

Figure 3. Share of secondary water supply in Nordhavn. The total water consumption of the first stage development is approximately 100,000 $\mathrm{m}^{3} / \mathrm{yr}$, increasing to an assumed 1.6 million $\mathrm{m}^{3} / \mathrm{yr}$ by 2060 . 
The concepts vary in the volume of secondary water used, from $0 \%$ in Concept 0 Business-as-usual to $100 \%$ in Concept 3 Desalination Drinking Water as a percentage of total water demand in Nordhavn (Figure 3). The concepts are explained in the following.

Concept 0 is the baseline concept, a system where the current water supply system in Copenhagen is extended into Nordhavn. The water will be abstracted from aquifers outside the city, treated through aeration and sand filtration, and then distributed to the city as potable water for all uses. Water is of drinking water quality with a relatively high hardness (362 $\mathrm{mg}$ as $\mathrm{CaCO}_{3} / \mathrm{L}$ ).

In the concept C1 Polluted Groundwater potable water will be distributed from Copenhagen's main drinking water system (as in Concept 0). Slightly polluted groundwater abstracted from the inner city of Copenhagen will be aerated and pass through sand filters, before it is distributed through a secondary network to be used in toilets and washing machines (assumed to be $35 \%$ of the total demand in Nordhavn). The water treatment plant for the non-potable supply will be situated in a park, with the potential for the public exhibition of treatment technologies. This water is not meeting drinking water quality criteria and has a hardness value equal to $\mathrm{CO}$.

In concept C2 Desalination Dual Distribution potable water will be distributed from Copenhagen's main drinking water system (as in Concepts CO and C1). All other water needs, equal to $91 \%$ of the total demand, will be based on desalinated brackish groundwater abstracted from wells near the coastline. The water will be treated to meet quality requirements for use in washing machines, toilets and dishwashers, but it will not necessarily attain drinking water quality. Water hardness level of final product water is assumed to be $108 \mathrm{mg}$ as $\mathrm{CaCO}_{3} / \mathrm{L}$. The water will be distributed through a secondary distribution network, while the treatment facility will not be open to the public. 
Concept C3 extends the desalination solution in Concept C2, to use it as the sole water supply for the area for both potable and non-potable purposes. The water will meet drinking water criteria and is assumed to have a water hardness of $108 \mathrm{mg}$ as $\mathrm{CaCO}_{3} / \mathrm{L}$. The water will be distributed through one pipe network.

Finally, concept C4 Rain and Gray Water delivers water for non-potable use through a decentralized distribution system, for example in a block of houses. Gray wastewater and rainwater collected from the roof are treated using advanced treatment techniques, to make the water fit for distribution and use in washing machines, toilets and dishwashers. The non-potable water supply will cover $85 \%$ of the total water demand. Technologies proposed in this concept are still in development, so the concept cannot be evaluated on equal terms with the other concepts, especially when it comes to the economy of the concept. Water hardness is assumed to be $108 \mathrm{mg}$ as $\mathrm{CaCO}_{3} / \mathrm{L}$. It is assumed that the treatment facility will be housed in the basement of the building, with the potential to show it to visitors.

\subsection{Economy}

The economic analysis shows that proposed concepts C1-C3 are 45 to $100 \%$ more costly than C0 Businessas-usual (Figure 4). C2 Desalination Dual Distribution is the most expensive concept, with an estimated NPV of -5.1 million $€$. The dual treatment and distribution of the non-potable supply account for $34 \%$ (C2) and $56 \%$ (C3) of the total NPV, which shows the significant added cost of running two systems in parallel. Savings made by operating the desalination plant for non-potable purposes do not compensate for the extra expense of the dual distribution, and the C3 Desalination Drinking Water option transpires as the most preferable concept of the two desalination concepts. Interestingly, the cost of C3, based on membrane treatment, is estimated at being just $17 \%$ more expensive than $\mathrm{C} 1$, based on simple aeration and sand filtration treatment. This is partly explained by $\mathrm{C} 1$ having the significant cost of conveying water through an inner part of Copenhagen to Nordhavn, whereas C3 can utilize a local groundwater resource. 


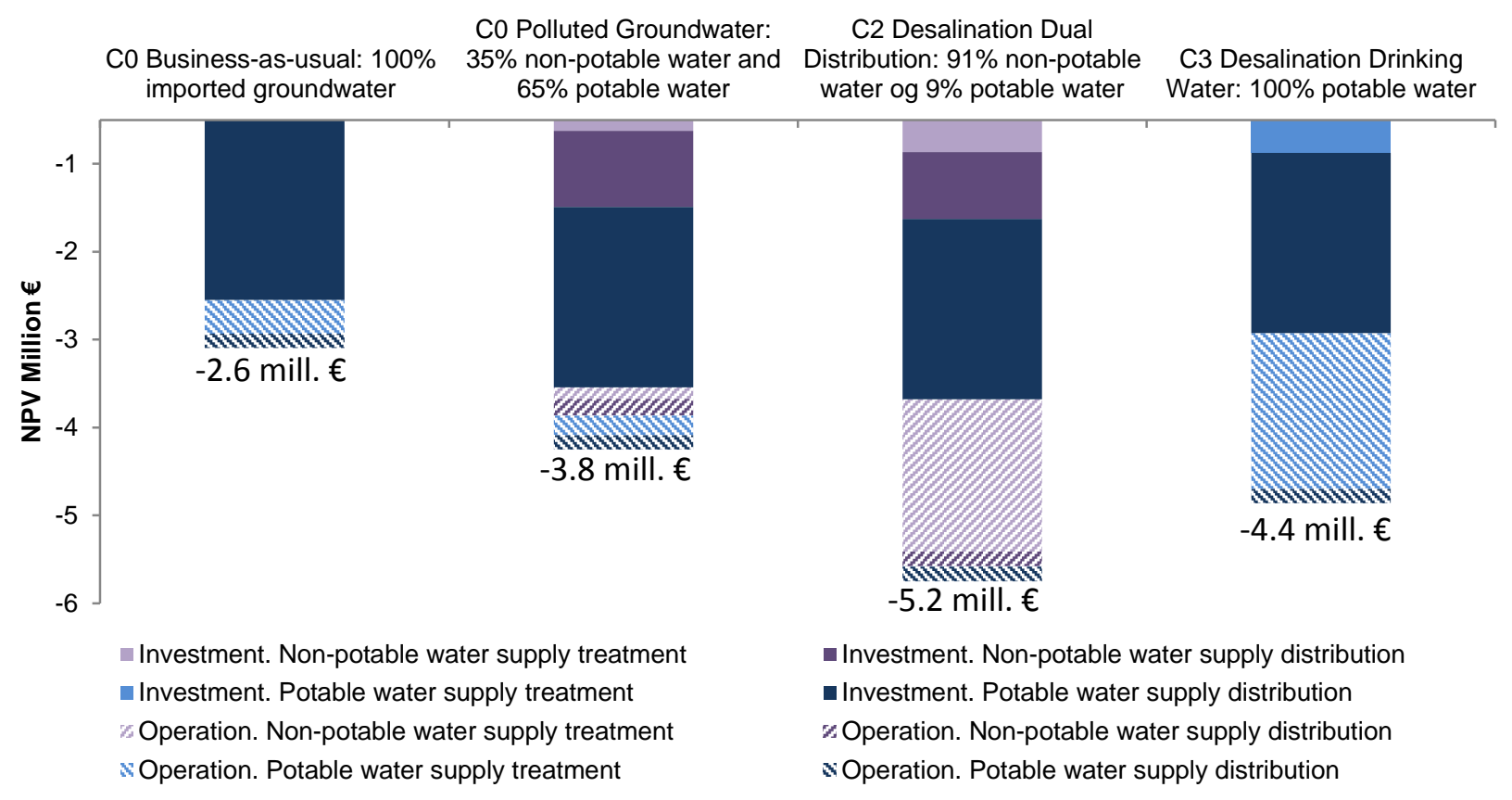

Figure 4. Net present value (NPV) of concepts $\mathrm{CO}-\mathrm{C} 3$ calculated over a 50 -year lifetime and at a $3 \%$ interest rate.

It is noted that investment in infrastructure (treatment and distribution) accounts for more than half the total cost for all the concepts. C3 Desalination Drinking Water has the lowest share of investment at 56\%, while CO Business-as-usual has the highest share of infrastructure cost at $80 \%$.

The assessment of cost only includes direct costs related to investment in and the operation of the proposed systems. Costs involved in the abstraction of imported groundwater or the construction of new well fields are not included, but these would likely add a marked extra cost to the CO Business-as-usual, if such measures are required for the future implementation of the EU Water Framework Directive.

C4 Rain and Gray Water is a demonstration project and cannot be assessed on equal economic terms with the other three concepts. Therefore, it has been left out of the financial evaluation. 


\subsection{Environmental impacts}

The environmental impact calculated by lifecycle assessment varies from less than $0.01 \mathrm{mPE}$ per $\mathrm{m}^{3}$ water delivered in Nordhavn to more than $0.15 \mathrm{mPE} / \mathrm{m}^{3}$ (Figure 5). Climate change impact and photochemical oxidant formation show the biggest differences across the five concepts. For these two impact categories it is the general picture that the treatment-intensive and energy-demanding concepts based on desalination and gray wastewater reuse $(\mathrm{C} 2, \mathrm{C} 3$ and $\mathrm{C} 4)$ cause an impact increase of $44 \%$ to $128 \%$ compared to the concepts based on more simple treatments ( $\mathrm{CO}$ and $\mathrm{C} 1$ ).

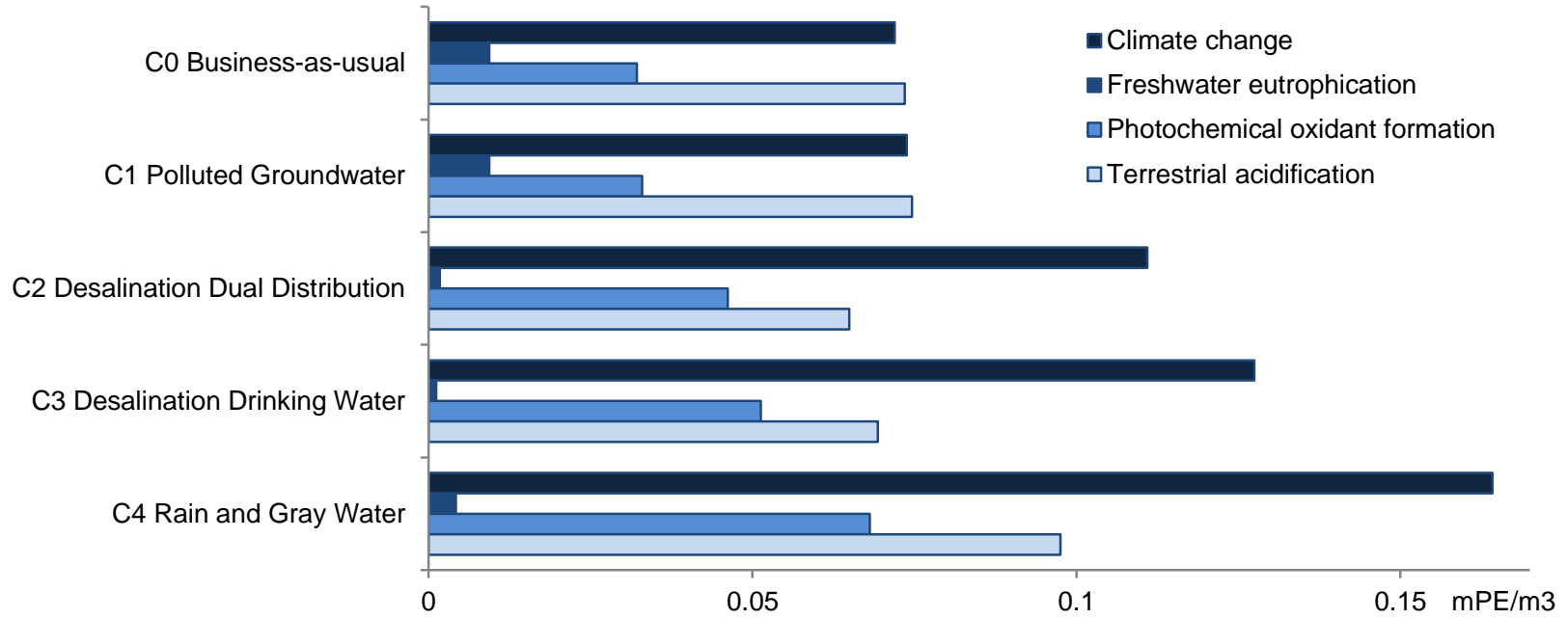

Figure 5. Results from the standard lifecycle assessment expressed as the normalized environmental impact of the concepts in micro person equivalents per $\mathrm{m}^{3}$.

When freshwater impacts are included, the evaluation of environmental performance is reversed. Since the desalination and rain/gray water harvesting concepts are much less dependent on freshwater resources, they also have a significantly lower impact on freshwater resources around Copenhagen (Figure 6). While C0 Business-as-usual and C1 Slightly Polluted Groundwater both have freshwater impacts greater than 15 $\mathrm{mPE} / \mathrm{m}^{3}$, the concepts based on desalination and rain/gray water harvesting $(\mathrm{C} 2, \mathrm{C} 3$, and $\mathrm{C} 4)$ have freshwater impacts less than $3 \mathrm{mPE} / \mathrm{m}^{3}$. The smallest impact $\left(0.04 \mathrm{mPE} / \mathrm{m}^{3}\right)$ on regional freshwater 
resources is obtained when desalination is the only option for both potable and non-potable water use in Nordhavn (C3 Desalination Drinking Water).

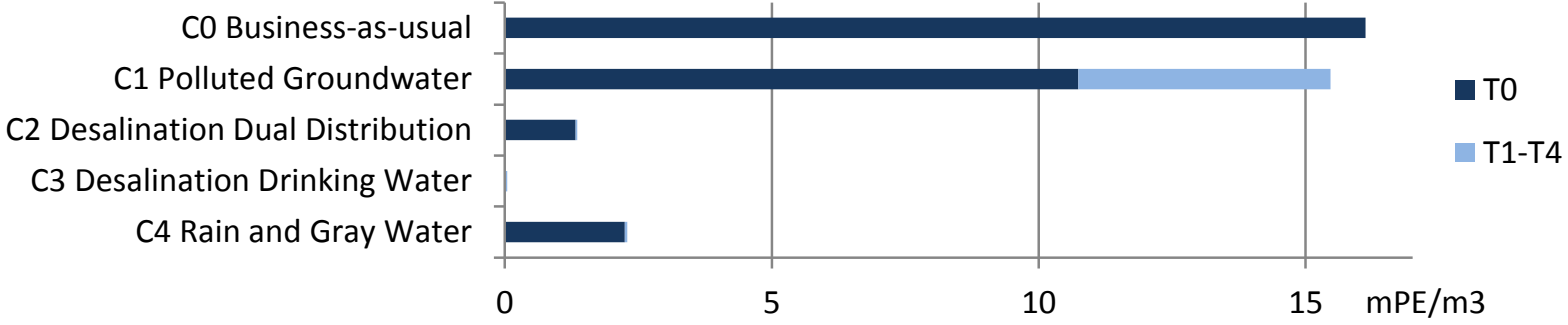

Figure 6. Normalized freshwater impacts. T0 represents the contributions from groundwater imported from outside Copenhagen. T1-T4 are contributions from locally sourced polluted groundwater (C1, approx. 5 $\left.\mathrm{mPE} / \mathrm{m}^{3}\right)$ and advanced treatment techniques $\left(\mathrm{C2}-\mathrm{C} 4\right.$, less than $\left.0.05 \mathrm{mPE} / \mathrm{m}^{3}\right)$.

The environmental assessment quantifies the dilemma of saving freshwater resources at the expense of increasing material and energy use and thus, for example, increasing the contribution to global warming. Even though desalination and water reuse may significantly increase the energy consumption of the water systems, the absolute impact of public water supply is markedly less than $1 \mathrm{PE} / \mathrm{m}^{3}$, and thus it is still a relatively small impact compared to other activities in society such as transport, heating, and food production. This is in line with the energy analysis of desalination schemes (Semiat, 2008).

\subsubsection{Weighted environmental impact and sensitivity assessment}

The weighted environmental impact (excluding freshwater withdrawal impacts) summarizes the estimated environmental impact and allows a direct comparison between the concepts. There is a negligible difference between CO Business-as-usual and C1 Slightly Polluted Groundwater while the treatmentintensive concepts $\mathrm{C} 2$ to $\mathrm{C} 4$ will increase the total environmental impact by 25 to $87 \%$ relative to C0 (Figure 7). 
Investment in infrastructure accounts for the majority of the total cost of concepts $\mathrm{CO}$ to $\mathrm{C} 3$, but the environmental sensitivity analysis reveals that infrastructure has an insignificant impact on the environmental performance of the concepts. A marked $50 \%$ reduction in material consumption will have a negligible $(<2 \%)$ influence on the weighted environmental impact as compared to the standard lifecycle assessment (Figure 7). As Copenhagen's existing drinking water is categorized as very hard, there are significant impacts associated with descaling and soap dosage for the concepts $\mathrm{C} 0$ and $\mathrm{C} 1$ that have no reduction in mineral content and hardness in the water treatment step. If these water quality impacts are $50 \%$ less than assumed (sensitivity scenario 2 ), it will lead to a $40 \%$ reduction in C0 and C1 impacts as compared to the standard lifecycle assessment. For the membrane- and rainwater-based C2 to C4 concepts, water is softer and sensitivity to water hardness impacts stands at less than $3 \%$. All four alternative concepts have their own major environmental burden (second to freshwater withdrawal impacts) within the operation phase. A change to produce electricity from renewables leads to environmental impact reductions ranging from 49 through 79\%, for predicted energy mixes in 2020, and 59 through $95 \%$ for 2035 .

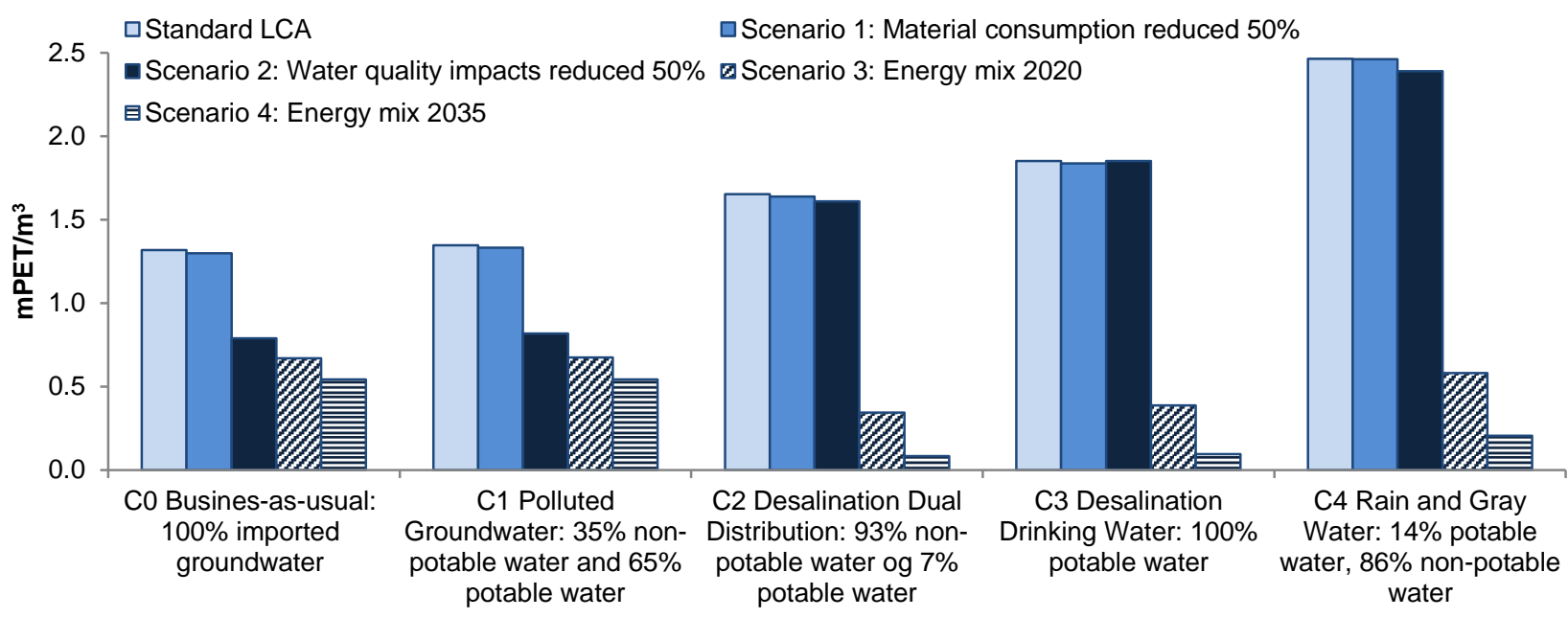

Figure 7. Weighted environmental impacts in person equivalents targeted from the standard LCA excluding freshwater impacts and four alternative scenarios proposed in the sensitivity analysis (2.2.2).. 
To sum up, the standard LCA assessment of environmental impacts (Figure 7) demonstrated that the CO Business-as-usual concept was advantageous, while increasing environmental impacts for the more infrastructure- and treatment-intensive concepts, based on dual distribution and desalinated/reclaimed water resources, were apparent. However, the sensitivity analysis showed that by changing power production from fossil-based resource consumption to renewable power production technologies, and increasing attention on freshwater withdrawal impacts, the treatment-intensive and locally sourced concepts $\mathrm{C} 3$ and $\mathrm{C} 4$ could be the environmentally preferable solutions for the future.

\subsection{Risk of infection}

The reverse QMRA was used to determine water quality requirements for laundry and toilet flushing applications, by comparing the risk involved in this process to a yearly acceptable risk of infection of $10^{-4}$ (Lechevallier and Buckley 2007). Based on the assumptions described above, an acceptable Norovirus aggregate concentration in secondary water is $500 \mathrm{NoV} / \mathrm{L}$ when used for laundry, $7 \mathrm{NoV} / \mathrm{L}$ when used for toilet flushing and $1 \mathrm{NoV} / \mathrm{L}$ if the risk of cross-connections is taken into account (Table 2). Borchardt et al. (2012) found up to 116 NoV genomic copies/L corresponding to 0.34 NoV aggregates/L (Teunis et al. 2008) in well protected aquifers used for water supply. Unprotected slightly polluted ground water (C1), e.g. under influence of sewage from leaking sewers, potentially contains higher than $1 \mathrm{NoV} / \mathrm{L}$.

Table 2. Estimated average concentrations in the secondary water, resulting in an average probability of infection of approximately $10^{-4}$ per year.

\begin{tabular}{lrr}
\hline & Average estimated concentration & Average probability of infection \\
\cline { 2 - 3 } & Norovirus/L & pr. year \\
\hline Laundry & 500 & $1 \cdot 10^{-4}$ \\
Toilet flushing & 7 & $1 \cdot 10^{-4}$ \\
Cross connections & 1 & $2 \cdot 10^{-4}$ \\
\hline
\end{tabular}


If contaminated such a source would need to be treated with methods other than aeration and sand filtration, such as membrane filtration, UV, or ozonization, in order to reduce the risk of infection to an acceptable level.In the case of $\mathrm{C} 2$, desalination treatment will reduce NoV concentration to between 3 and $7 \log$ units (WHO, 2011) and ensure concentrations below $1 \mathrm{NoV} / \mathrm{L}$, if the raw saline water is not or is only slightly influenced by wastewater. In the case of C4, contamination of the grey water by NoV will occur when residents are infected. The faecal load of grey water is approximately $0.1 \mathrm{~g}$ faeces/person/day (Ottoson and Stenström, 2003). Assuming a production of $100 \mathrm{~L}$ of grey water/person/day, $10^{8} \mathrm{NoV}$ genecopies/g faeces (Tu et al 2008) and 400 gene copies/virus aggregate (Teunis et al 2008) a NoV concentration of $250 \mathrm{NoV}$ aggregates/L is a likely level when residents are infected. A grey water reuse system will therefore need to include some kind of disinfection, such as UV, to be safe. As an alternative to improved treatment, reuse could be restricted to laundering, and a systematic surveillance method, employed to reduce the probability of cross-connections, could be implemented. Improved treatment, reduction of the risk of cross connections and restriction of use to laundry only will all make C1 and C4 less economic advantageous. The microbial water quality may therefore influence the economic evaluation in favour of C2 compared to C1 and C4.

However, it should be noted that QMRA is associated with a great deal of uncertainty. In this case, degree of NoV aggregation, estimation of the transfer of NoV from hands to mouth and the number and frequency of apartments affected by cross-connections are considered to be associated with the highest uncertainty.

\subsection{User perspectives}

User perspectives were explored in a qualitative study. This section describes the different values, worries and aspects of household practises that were discovered through the study of user perspectives; however, the user perspectives herein are not directly related to the different concepts. Since there was no marked 
difference in the responses between respondents already living with secondary water quality and other participants, the answers will be reported together for the two groups.

\subsubsection{Attitudes to and trust in secondary water quality}

Notably, the more experienced users expressed satisfaction with the system and claimed they would choose it again based on their current knowledge. One exception was the elected head of one of the local housing associations that played a big role in driving the implementation process. She stated that managing a system with secondary water quality was so complicated and bureaucratic that she would not do it again. These difficulties indicate the novelty of using secondary water qualities in Denmark as an alternative to the current, traditional system.

All participants in the study were in general very positive towards the use of secondary-quality water in the home, based on the assumption that this helps to conserve clean groundwater and thus contributes to sustainable water management. Hence, the participants thought it a positive move to use this type of water for toilets, washing machines, washing cars, and watering the garden. All the respondents were positive about moving into a property using water of secondary quality, and those who already had installed water systems of this type wished to continue living in a home with these installations.

Environmental concerns and the opportunity to save unpolluted groundwater were the most important incentives for the respondents to use water of secondary quality. In the quick poll, 17 of the 51 optional comments related to concerns about pure groundwater. The participants explained that the use of secondary water supply is an important step in taking care of drinking water resources and the environment. Several participants emphasized that using clean groundwater for toilet flushing is a waste of resources and that we should conserve clean groundwater, as it is a limited resource. In addition, climate change and overloaded sewers were seen by several users as an incentive to use rainwater for toilet flushing. 
It should be noted that this clear link between the use of secondary water and water resources, and the understanding of groundwater as a limited resource, was established by the respondents. This also applies to using storm water as a secondary source, as a way of addressing overloaded sewers. However, the main point was that the users were very positive about secondary water sources as a way of addressing sustainable development.

The respondents were very confident that there would be no risk to their health by introducing secondary water qualities into their homes. This was based on high trust in the system supplying the water, based on the users' experience and on their idea of the system being based on 'professionalism' and 'independent' of economic interests. Inside their home, more participants mentioned that they would take responsibility for their children learning how to use the water, e.g. not to drink from the toilet. A few raised concerns about the process involved in cleaning the water, if this included 'chemicals' that might remain in the water.

\subsubsection{User knowledge and involvement in the water systems}

Most of the participants saw no problems with having two sets of pipes in their home. Some participants said that it could actually result in the creation of an attractive design, including different colors or other characteristics showing the different water qualities, in order to avoid mistakes. This trust in the secondary water supply is related to access to knowledge about the system and water quality. Most of the respondents expressed a wish to learn about the system if it was implemented, even if they were not sure they would actually use this possibility in their homes. Furthermore, several ideas on the greater visibility of the system in general were presented, e.g. by opening up the water works to the general public and perhaps even putting on some sort of supply system exhibition. In this way, the secondary water supply would also be seen as an interesting way of creating an attractive identity for the homes/local area.

The users seemed to be confident that professionals would handle the provision of different water qualities in a secure manner. Meanwhile, the professionals showed some reluctance regarding introducing different grades of water into homes, because of safety issues. This can be interpreted as the result of the 
responsibility of the current water system being largely based on professional knowledge and management. Knowledge seems to be a key issue in this case. The survey also shows that the users have rather limited knowledge about the system and the interconnected issues of environment and resources. However, as these are complex, it is not surprising that several misunderstandings or idealistic logic were prevalent amongst the participants, which underlines the rather limited relationship between users and professionals.

During the professionals' workshop, it was mentioned that engaging users would be an important element in creating a robust system in relation to safety, the environment, and consumption. At the same time the users pointed out that access to knowledge about the water system and water quality is an important factor in trust and participation, even though they may never use this information. If knowledge could be displayed and communicated in interesting ways, the users expressed that they would be interested in finding out more about the system.

\subsection{Cross-disciplinary discussion and evaluation of the concepts}

The results presented in sections 3.2 to 3.5 are used as the basis for a cross-disciplinary discussion of the concepts. A number of criteria were assessed qualitatively and then assigned a value from a five step scale with the interpretation that a concept performs: -2: much worse, -1 : worse, 0 : same as, 1 : better, and 2 much better than CO Business-as-usual. The evaluation of the criteria can be summarized as:

Water self-sufficiency. Copenhagen is highly reliant on water imports from areas outside the city. Concepts increasing water self-sufficiency in the city will make Copenhagen less dependent on water allocation from outside the local jurisdiction area. All four concepts will increase water self-sufficiency.

Integration with resource management of the city. Urban water systems are integrated into multiple forms of infrastructure within the city, for example energy systems (Olsson, 2012) and waste systems. Local groundwater abstraction (C1) can be integrated into rainwater infiltration schemes. Advanced wastewater treatment in concept $\mathrm{C} 4$ creates the potential for energy and nutrient recovery and eventual integration 
into the municipal waste system. Although desalination ( $C 2$ and $\mathrm{C} 3$ ) is energy-intensive, the total impact on the city's energy system is assumed to be of minor importance (Semiat, 2008).

Flexibility in regard to scaling. The city is under constant development, and even plans for a local area like Nordhavn may change several times before full implementation decades into the future. It is therefore relevant to consider flexibility in regard to scaling the proposed concepts. The cost estimates in this study revealed significant investment, which it is assumed will be challenging in view of future possible requirements for down- or up-scaling. In particular, C1 Slightly Polluted Groundwater appears inflexible in this respect, as piping through the inner city and treatment facilities (aeration and sand filters) are not flexible to meet changing water demands. On the other hand, the desalination concepts (C2 and C3) and the decentralized gray and rainwater harvesting (C4) could be scaled easily in line with greater or smaller future water demands. Desalination plants are typically built in modules (Fritzmann et al., 2007), and so adding or removing a module will allow for scaling over time. Gray and rainwater harvesting is proposed as a decentralized system, so scaling would follow in line with the stepwise development of the area.

Experimental value. A challenging or new water supply concept will have experimental value for technology providers, authorities, and end-users alike. The concepts will provide knowhow for providers and authorities that they can use in other projects and systems. Especially gray water reclamation and rainwater harvesting will introduce challenges and new knowledge for technology providers and authorities that can be used in other projects and be of value outside Nordhavn. For local end-users, these new concepts could provide empowerment, through increased insights and interest in the urban water cycle, and thereby enable the community to take responsibility and act in relation to water challenges in cities. This will have great societal value. As all four proposed concepts are different from current Danish water supply practice, they will all have some experimental value.

Demonstration value. Changing the water supply paradigm in the area could serve as a demonstration of technology and knowhow. In a Danish context, all four alternative concepts would serve as showcases for 
alternative water management, since they are markedly different from the traditional groundwater-based supply in place today. In an international context, C4 Rain and Gray Water especially would function as a showcase.

Identity and branding. A concept could support ambitions for an area to be 'green' and 'sustainable', for example by reducing freshwater impacts, reducing the burden on the surrounding environment, increasing water self-sufficiency, and facilitating resource recovery. C1 Polluted Groundwater and C4 Rain and Gray Water offer the opportunity for the public to visit and show the system to visitors and would support the identity and branding of Nordhavn as a forward-thinking development.

Resilience toward natural changes. A diversified water system, with flexibility for scaling and adaptation to changes in the surrounding area, would be resilient to future changes to the urban water infrastructure. Such changes could be driven, for example, by population growth or decline, climate change, or new political targets for water reuse. C1 Slightly polluted Groundwater stands out due to its relatively low investment costs and reliance on fresh groundwater resources. Since scaling of $\mathrm{C} 1$ is difficult, and it would be dependent on fresh groundwater of a sufficient quality, it would not be very flexible in the case of increased pressure on local freshwater resources, and abandoning the concept at a later stage would lock up significant costs in the treatment plant and water distribution piping. The other three concepts could all be scaled gradually and are based on water resources independent of natural changes. Therefore, C2-C4 are considered resilient in respect to natural changes. 
Table 3. Evaluation of concepts $C 1$ to C4 in relation to CO Business-as-usual. The evaluation criteria have been assessed on a scale of -2 through 2, where -2 is negative compared to $\mathrm{CO}$ and 2 is positive as compared to CO. O means that the concept is unchanged compared to CO.

\begin{tabular}{|ll|cccc|}
\hline Criteria & Evaluation method (section) & C1 & C2 & C3 & C4 \\
\hline Costs & Quantitative (3.2) & -1 & -2 & -1 & $?$ \\
\hline Lifecycle assessment & Quantitative (3.3) & 0 & -1 & -1 & -2 \\
\hline Freshwater impacts & Quantitative (3.3) & 0 & 2 & 2 & 2 \\
\hline Risk assessment & Quantitative (3.4) & -1 & 1 & 1 & -2 \\
\hline Water self-sufficiency & Qualitative (3.6) & 1 & 1 & 2 & 1 \\
\hline Integration with resource management & Qualitative (3.6) & 1 & 0 & 0 & 1 \\
\hline Flexibility towards scaling & Qualitative (3.6) & -2 & -1 & 1 & 2 \\
\hline Experiemental value - knowhow & Qualitative (3.6) & 1 & 1 & 1 & 2 \\
\hline Experimental value - empowerment & Qualitative (3.6) & 1 & 1 & 1 & 1 \\
\hline Demonstration value - showcase & Qualitative (3.6) & 1 & 1 & 0 & 2 \\
\hline Identity and branding & Qualitative (3.5 \& 3.6) & 1 & 0 & 0 & 2 \\
\hline Resilience towards natural changes & Qualitative (3.6) & -1 & 1 & 1 & 1 \\
\hline
\end{tabular}

In this comparison of the concepts we have not attempted to assign a weight to any individual criterion. In summary, the discussion (Table 3) shows that no concept performs markedly better or worse than the others. Several criteria are judged unchanged or positive for all four concepts, including Freshwater Impacts, Integration with Resource Management, Experimental Value, Demonstration Value, and Identity and Branding (Table 3). It is also noteworthy that all proposed concepts perform worse than Co Business-asusual for the Costs and Lifecycle Assessment criteria. Environmental impacts accounted for in the lifecycle assessment exclude Freshwater Impacts, which are positive for the proposed concepts $\mathrm{C} 2-\mathrm{C} 4$. This highlights the paradox that a reduced freshwater impact may come at the cost of more intensive water treatment and increased environmental impacts, such as contributions to climate change.

\section{Conclusion}

Our project aimed at comparing results acquired by employing a mix of quantitative and qualitative assessment methods. It was found that multiple tools are available for a holistic assessment of alternative water supply options, from economic, environmental, risk, and user (social) perspectives. Comparing the 
results from the individual criteria exemplifies the complexity behind decision-making regarding modern water systems. However, the presentation of unweighted criteria results and a comparison of quantitative as well as qualitative criteria forms a basis for transparent decision-making and emphasizes the consequences, priorities as well as the compromises that need to be made by decision-makers. For our specific case study in Nordhavn, Copenhagen, the concrete outcomes of the study points have been:

- All four studied concepts are expected to be significantly more expensive than the Business-asusual option.

- Standard environmental lifecycle assessment shows that treatment-intensive solutions such as desalination or gray water-based concepts will have a greater impact on the environment compared to the groundwater-based system, namely CO Business-as-usual.

- However, desalination or gray water-based systems may become the preferable option in the near future because: 1) Including the impact on freshwater resources in the environmental assessment markedly supports the implementation of resources other than groundwater, and 2) a power production largely based on renewable energy sources as projected for 2020 will make intensive water treatment environmentally viable.

- A quantitative microbial risk assessment indicates that poor microbial secondary water quality influences economic evaluation, reduces reusability, or requires intensified surveillance, in order to avoid cross-contamination.

- Participants in the user perspective study are in general very positive in relation to the use of a secondary water supply in the home, based on the assumption that this would help to conserve clean groundwater and thus contribute to sustainable water management.

- Environment, resources, payment, comfort, trust, local identity, and knowledge were identified as important user perspectives. 
- Knowledge and relations between users and professionals seem to be key issues. The survey points out that users have rather limited knowledge about the system and the interconnected issues of the environment and resources. Still, they have a high degree of confidence that professionals in the field will handle the provision of more water qualities in a secure manner. Correspondingly, the professionals recognise users as important actors in the development of water systems.

The combination of quantitative and qualitative assessments has led to non-conclusive results on the viability of implementing a specific secondary water supply in Nordhavn. However, our approach has exposed an essential dilemma for the decision-makers and two main questions remain for them to consider: 1) Is a reduction in groundwater imports essential? 2) Should a secondary water supply in Nordhavn act as a demonstration project showcasing state-of-the-art- technology and helping to create an identity for local citizens? Each proposed concept might be a viable option, depending on the answers to these questions.

\section{Acknowledgements}

The project was carried out by a working group including the authors and partners represented by M.-B. B. Poulsen, L. Tarp-Johansen, K. Zambrano (HOFOR); S. Vigsø, K. Keiding (Grundfos); L. Alsbjørn (Aalborg University); M. Ejsing (Municipality of Copenhagen); M. Schmidt, H.-M- F. Møller (Grontmij); R. P. Hansen (Danish Nature Agency); K. Ledgaard (CPH City and Port Development); and H.J. Albrechtsen, K. ArnbjergNielsen (Technical University of Denmark). The project was funded by the partners and the Danish Agency for Science, Technology and Innovation. 


\section{References}

Baitz, M., Colodel, C.M., Kupfer, T., Pflieger, J., Schuller, O., Hassel, F., Kokborg, M., Köhler, A., Stoffregen, A., 2012. GaBi Database \& Modelling Principles 2012. Leinfelden - Echterdingen, Germany.

Borchardt, M.A., Spencer, S.K., Kieke, B.A., Lambertini, E., Loge, F.J., 2012. Viruses in nondisinfected drinking water from municipal wells and community incidence of acute gastrointestinal illness. Environ. Health Perspect. 120, 1272-9.

Charlton, M.B., Arnell, N.W., 2011. Adapting to climate change impacts on water resources in England-An assessment of draft Water Resources Management Plans. Glob. Environ. Chang. 21, 238-248.

Chen, Z., Ngo, H.H., Guo, W., 2012. A critical review on sustainability assessment of recycled water schemes. Sci. Total Environ. 426, 13-31.

CPH CP, 2012. Inner Nordhavn - From idea to project. Copenhagen City and Port, Copenhagen, Denmark.

Danish Ministry of the Environment, 2001. Bekendtgørelse om vandkvalitet og tilsyn med vandforsyningsanlæg (Executive order on water quality and authority on water supply).

Dolnicar, S., Hurlimann, A., Grün, B., 2014. Branding water. Water Res. 57C, 325-338.

European Commission, 2012. The EU Water Framework Directive - integrated river basin management for Europe [WWW Document]. URL http://ec.europa.eu/environment/water/waterframework/index_en.html (accessed 1.14.13).

Fritzmann, C., Löwenberg, J., Wintgens, T., Melin, T., 2007. State-of-the-art of reverse osmosis desalination. Desalination 216, 1-76.

Godskesen, B., Hauschild, M., Rygaard, M., Zambrano, K., Albrechtsen, H.-J., 2012. Life cycle assessment of central softening of very hard drinking water. J. Environ. Manage. 105, 83-89.

Godskesen, B., Hauschild, M., Rygaard, M., Zambrano, K., Albrechtsen, H.-J., 2013. Life-cycle and freshwater withdrawal impact assessment of water supply technologies. Water Res. 47, 2363-2374.

Goedkoop, M., Heijungs, R., Huijbregts, M., Schryver, A. De, Struijs, J., Zelm, R. van, 2009. ReCiPe 2008, A life cycle impact assessment method which comprises harmonised category indicators at the midpoint and the endpoint level; First edition Report I: Characterisation, A life cycle impact .... Den Haag, The Netherlands.

Grant, S.B., Fletcher, T.D., Feldman, D., Saphores, J.-D., Cook, P.L.M., Stewardson, M., Low, K., Burry, K., Hamilton, A.J., 2013. Adapting Urban Water Systems to a Changing Climate: Lessons from the Millennium Drought in Southeast Australia. Environ. Sci. Technol. 47, 10727-10734.

ISO, 2008. ISO 14044: Environmental Management - Life cycle assessment - Requirements and Guidelines. International Organization for Standardization, Geneva, Switzerland. 
Københavns Kommune, 2012. Vandforsyningsplan 2012. Udkast (Water supply plan 2012. Draft). Copenhagen, Denmark.

Lamichhane, K.M., Babcock, R.W., 2013. Survey of attitudes and perceptions of urine-diverting toilets and human waste recycling in Hawaii. Sci. Total Environ. 443, 749-56.

Lechevallier, M., Buckley, M., 2007. Clean Water: What is acceptable microbial risk?, The American Biology Teacher. Washington, D.C., USA.

Lindegaard, H., 2008. Artefacts as co-constructed and socio-material phenomena. Ethnol. Scand. 104-115.

Mainali, B., Pham, T.T.N., Ngo, H.H., Guo, W., Miechel, C., O’Halloran, K., Muthukaruppan, M., Listowski, A., 2013. Vision and perception of community on the use of recycled water for household laundry: a case study in Australia. Sci. Total Environ. 463-464, 657-66.

Muñoz, I., Fernández-Alba, A.R., 2008. Reducing the environmental impacts of reverse osmosis desalination by using brackish groundwater resources. Water Res. 42, 801-11.

NRMMC et al., 2006. National Guidelines for Water Recycling: Managing Health and Environmental Risks (Phase 1). The Environment Protection and Heritage Council, the Natural Resource Management Ministerial Council and the Australian Health Ministers' Conference, Canberra, Australia.

O'Toole, J., Sinclair, M., Leder, K., 2009. Transfer rates of enteric microorganisms in recycled water during machine clothes washing. Appl. Environ. Microbiol. 75, 1256-63.

O’Toole, J., Sinclair, M., Malawaraarachchi, M., Hamilton, A., Barker, S.F., Leder, K., 2012. Microbial quality assessment of household greywater. Water Res. 46, 4301-13.

Olsson, G., 2012. Water and energy. IWA Publishing, London, United Kingdom.

Ottoson, J., Stenström, T.A., 2003. Faecal contamination of greywater and associated microbial risks. Water Res. 37, 645-55.

PE International, 2012. PE LCIA Survey 2012 [WWW Document]. GaBi LCIA Doc. URL http://www.gabisoftware.com/support/gabi/gabi-Icia-documentation/pe-Icia-survey-2012-weighting/ (accessed 3.11.14).

Rosenbaum, R.K., Bachmann, T.M., Gold, L.S., Huijbregts, M.A.J., Jolliet, O., Juraske, R., Koehler, A., Larsen, H.F., MacLeod, M., Margni, M., McKone, T.E., Payet, J., Schuhmacher, M., Meent, D., Hauschild, M.Z., 2008. USEtox - the UNEP-SETAC toxicity model: recommended characterisation factors for human toxicity and freshwater ecotoxicity in life cycle impact assessment. Int. J. Life Cycle Assess. 13, 532546.

Rusin, P., Maxwell, S., Gerba, C., 2002. Comparative surface-to-hand and fingertip-to-mouth transfer efficiency of gram-positive bacteria, gram-negative bacteria, and phage. J. Appl. Microbiol. 93, 585592. 
Rygaard, M., Alsbjørn, L., Ejsing, M., Godskesen, B., Hansen, R., Hoffmann, B., Jørgensen, C., Ledgaard, K., Møller, H.-M.F., Poulsen, M.-B.B., Schmidt, M., Tarp-Johansen, L., Vigsø, S., Zambrano, K., 2013. Sekundavand i Nordhavn (A secondary water supply for Nordhavn). Kgs. Lyngby, Denmark.

Rygaard, M., Arvin, E., Bath, A., Binning, P.J., 2011a. Designing water supplies: Optimizing drinking water composition for maximum economic benefit. Water Res. 45, 3712-3722.

Rygaard, M., Binning, P.J., Albrechtsen, H.-J., 2011b. Increasing urban water self-sufficiency: New era, new challenges. J. Environ. Manage. 92, 185-194.

Seitz, S.R., Leon, J.S., Schwab, K.J., Lyon, G.M., Dowd, M., McDaniels, M., Abdulhafid, G., Fernandez, M.L., Lindesmith, L.C., Baric, R.S., Moe, C.L., 2011. Norovirus infectivity in humans and persistence in water. Appl. Environ. Microbiol. 77, 6884-8.

Semiat, R., 2008. Energy Issues in Desalination Processes. Environ. Sci. Technol. 42, 8193-8201.

Shirasaki, N., Matsushita, T., Matsui, Y., Oshiba, A., Ohno, K., 2010. Estimation of norovirus removal performance in a coagulation-rapid sand filtration process by using recombinant norovirus VLPs. Water Res. 44, 1307-16.

Storey, M.V., Deere, D., Davison, A., Tam, T., Lovell, A.J., 2007. Risk management and cross-connection detection of a dual reticulation system, in: Anderson, J.M., Stuetz, R., Khan, S.J. (Eds.), Water Reuse and Recycling. Proceedings of the 3rd Australian Water Association Water Reuse and Recycling Conference. UNSW Publishing and Printing Services, Sydney, Australia, pp. 459-466.

Teunis, P.F.M., Moe, C.L., Liu, P., Miller, S.E., Lindesmith, L., Baric, R.S., Le Pendu, J., Calderon, R.L., 2008. Norwalk virus: how infectious is it? J. Med. Virol. 80, 1468-1476.

The Ministry of Climate Energy and Building, 2013. The Danish Climate Policy Plan Towards a low carbon society. Copenhagen, Denmark.

Tu, E.T.-V., Bull, R.A., Kim, M.-J., Mclver, C.J., Heron, L., Rawlinson, W.D., White, P.A., 2008. Norovirus excretion in an aged-care setting. J. Clin. Microbiol. 46, 2119-21.

Van der Bruggen, B., Goossens, H., Everard, P.A., Stemgee, K., Rogge, W., 2009. Cost-benefit analysis of central softening for production of drinking water. J. Environ. Manage. 91, 541-549.

Westrell, T., 2006. Drinking water consumption patterns in Sweden. J. Water Health 4, $511-522$.

WHO, 2011. Safe Drinking-water from Desalination. Geneva, Switzerland. 